\title{
Renal Cell Carcinoma in Kindey Allografts: Case Report Series and Review of the Literature
}

\author{
Sayed Husain*, Felix Perez, Rada Gerbi, Mariella Goggins, Anita Patel and Venkat KK
}

Department of Nephrology \& Hypertension, Henry Ford hospital, Wayne State university, USA

\begin{abstract}
The overall incidence of malignancy after renal transplantation is three to five times higher than in general population. As a result malignancy is the third most common cause of death in renal recipients. Three cases are given below of de novo renal allograft tumor occurring after transplantation. Case 1 is about a 57-year old female patient who underwent kidney transplant (LRKT) with zero haplotype match from her cousin and the case 2 discuss about a 45-year old female who developed ESRD secondary to chronic glomerulonephritis v/s hypertensive sclerosis. Last case report discusses about 46-year old Caucasian male with a history of $\lg \mathrm{A}$ and Granulomatosis with polyangiitis received LRKT from his brother.
\end{abstract}

\section{Introduction}

The overall incidence of malignancy after renal transplantation is three to five times higher than in general population. As a result malignancy is the third most common cause of death in renal recipients [1]. Non melanoma skin cancer (NMSC) and lymphoma are the most common malignancies followed by renal cell carcinoma (RCC) [1]. The classic triad of hematuria, abdominal pain and flank pain is not a feature of RCC transplant. The median time lapse between transplantation and tumor diagnosis is between 3 and 19 years or longer as reported in literature. Most of the RCC are found in the recipient's native kidneys and only few cases of RCCs in renal allograft have been reported so far. As a result allograft tumor is an unusual and rare complication. Obesity, analgesic abuse, tobacco, repeated pyelonephritis along with immunosuppression is the risk factors facilitating the development of allograft and native RCC [2]. Israel Penn Transplant Tumor Registry has reported only 45 cases of allograft RCC [3]. Genetic analysis and immunologic human leukocyte antigen typing should be assessed on the basis of tumor specimen to identify the donor or recipient origin of RCC. Treatment options for these cancers include radiofrequency ablation and partial or total nephrectomy, depending on the patient's performance status and staging of the RCC. Three cases are given below of de novo renal allograft tumor occurring after transplantation.

\section{Case Reports}

\section{Case 1}

A 57-year old Hispanic female with a history of HTN and End Stage Renal Disease (ESRD) secondary to Systemic lupus Nephritis (SLE) in December 1994, underwent living related kidney transplant (LRKT) with zero haplotype match from her cousin. She had a baseline creatinine of $0.9-1.1 \mathrm{mg} / \mathrm{dl}$. There was no history of malignancies in her family. She was placed on Imuran, Cyclosporine (CSA) and steroids. Due to steroid induced complications her Imuran was discontinued and Cellcept was started and steroids were tapered. In 2008, she had a $\mathrm{CT}$ of abdomen due to abdominal pain and a $10 \mathrm{~mm}$ enhancing mass in left native kidney was discovered. Interventional radiology (IR) guided biopsy was performed which was inconclusive and showed no discrete mass lesion with deeper cuts. The mass was later treated with cryoablation. Follow up MRI was performed in November 2011, which showed $1.3 \mathrm{~cm} \times 1.3 \mathrm{~cm}$ mass in the lower pole of the right allograft but no changes were noted in the prior ablation site of the left native kidney. CSA was switched to Rapamune. A repeat biopsy showed Conventional Clear type tumor-Grade1 and as result required allograft nephrectomy and was started on hemodialysis (HD). Left native nephrectomy was planned due to suspicion for being the primary source. Unfortunately, her donor was also diagnosed with RCC (Figure 1).

\section{Case 2}

A 45-year old African American female with a history of coronary artery disease with stent, hypertension during pregnancy and proteinuria as a teenager developed ESRD secondary to chronic glomerulonephritis v/s hypertensive sclerosis. Patient had no family history of any malignancies. Initially, hemodialysis was started in October 1997, for about 3 years. Later, she underwent an LRKT from her sister with one haplotype match in July 2001. Her transplant was complicated with severe cellular rejection with necrotizing arteriolitis and thrombosis, and treated with Thymoglobulin, OKT3 and plasmapheresis. She later

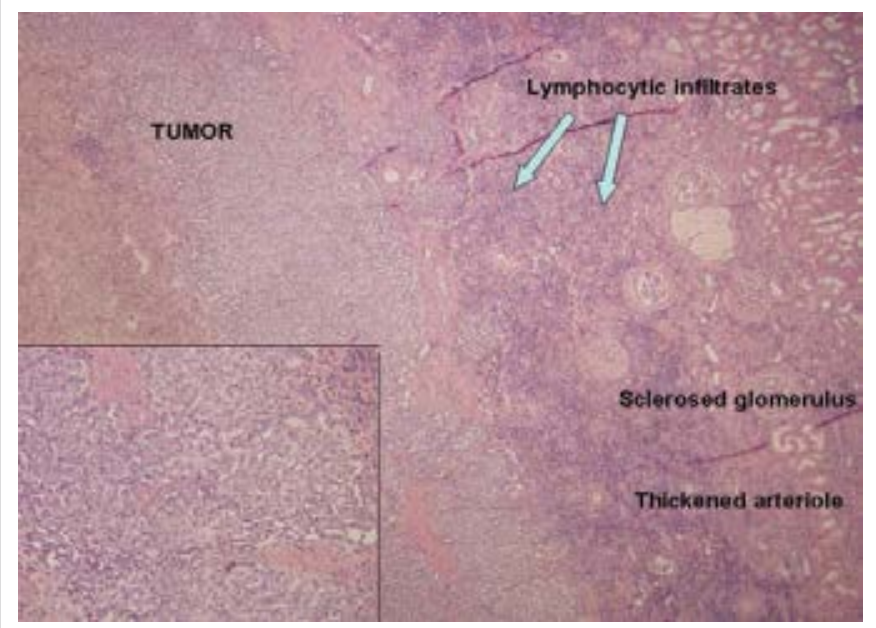

Figure 1: Biopsy Report Case\#1.

*Corresponding author: Sayed Husain, Department of Nephrology \& Hypertension Henry Ford hospital, Wayne State university, USA, E-mail: hus9007@hotmail.com

Received March 12, 2013; Accepted July 18, 2013; Published July 22, 2013

Citation: Husain S, Perez F, Gerbi R, Goggins M, Patel A, et al. (2013) Renal Cell Carcinoma in Kindey Allografts: Case Report Series and Review of the Literature. J Nephrol Ther 3: 132. doi:10.4172/2161-0959.1000132

Copyright: ( 2013 Husain S, et al. This is an open-access article distributed under the terms of the Creative Commons Attribution License, which permits unrestricted use, distribution, and reproduction in any medium, provided the original author and source are credited. 
maintained good graft function with creatinine in the range of 1.5$1.6 \mathrm{mg} / \mathrm{dl}$.on steroids, Cellcept, Prograf and Rapamune. In 2003, her immunosuppressants (IS) were changed to Cellcept and Cyclosporine due to toxicities. Subsequent rejection occurred in 2010 and required intravenous steroids. She developed chronic intermittent microscopic hematuria which led to an Ultrasound (U/S) finding of $1.8 \mathrm{~cm}$ hypo echoic lesion on the lateral aspect of the graft in 2010. Due to unknown cardiac stent MRI was not performed. Urological workup showed normal cystoscopy and cytology. However, subsequent ultrasounds within 4-5 months showed a complex cyst of $1 \times 1.2 \mathrm{~cm}$ along with the mass which had regressed to $1.3 \mathrm{~cm}$. Radiology raised suspicion for post transplant lymphoproliferative disorder (PTLD), which requires biopsy of the graft showing papillary renal cell carcinoma with potential mulitfocality of the lesion. As a result, transplant nephrectomy of the right kidney was performed on September 2011. Her current status is that she is on hemodialysis but the status of the donor is unknown (Figure 2).

\section{Case 3}

A 46-year old Caucasian male with a history of Ig A and Granulomatosis with polyangiitis (Wegener's, GPA) received LRKT from his brother in 1997, which was performed at the University of Michigan. GPA was treated with Cyclophosphamide, Cellcept and prednisone. Post transplant, he was administered with cyclosporine and Cellcept. His graft function was stable for the last 14 years with creatinine around $1.9-2.2 \mathrm{mg} / \mathrm{dl}$. He visited the institute due to failing kidney function as his creatinine level increased from baseline 2.26 $\mathrm{mg} / \mathrm{dl}$ to $6.8 \mathrm{mg} / \mathrm{dl}$. His U/S and CT scan were indicative of a solid and vascular lesion of $3.1 \times 3.3 \times 3.6 \mathrm{~cm}$ which was a complex cyst in the anterior aspect of the left allograft suspicious for PTLD v/s RCC. In the interim he was started on HD. Urology was consulted for a-typical cytology of the urine. Cystoscopy was performed and found to be normal; as a result, fluorescent in situ hybridization (FISH) was performed. He underwent transplant nephrectomy in September 2011, and biopsy was performed on the same day showing papillary renal carcinoma (Figure 3 and Table 1).

\section{Discussion}

Papillary carcinoma is the second most common frequent carcinoma observed in 10-15\% cases of RCCs. it is also common in

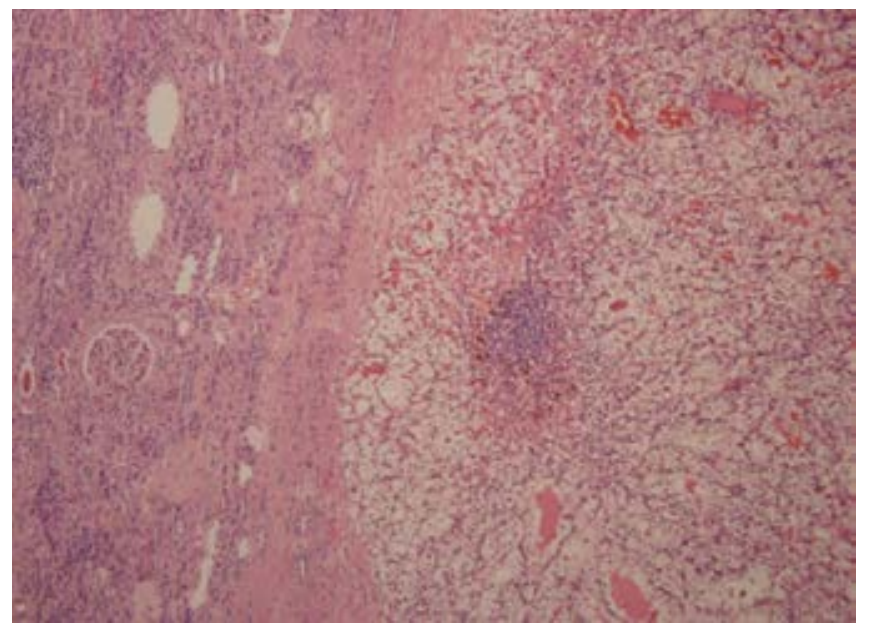

Figure 2: Biopsy Case\#2.

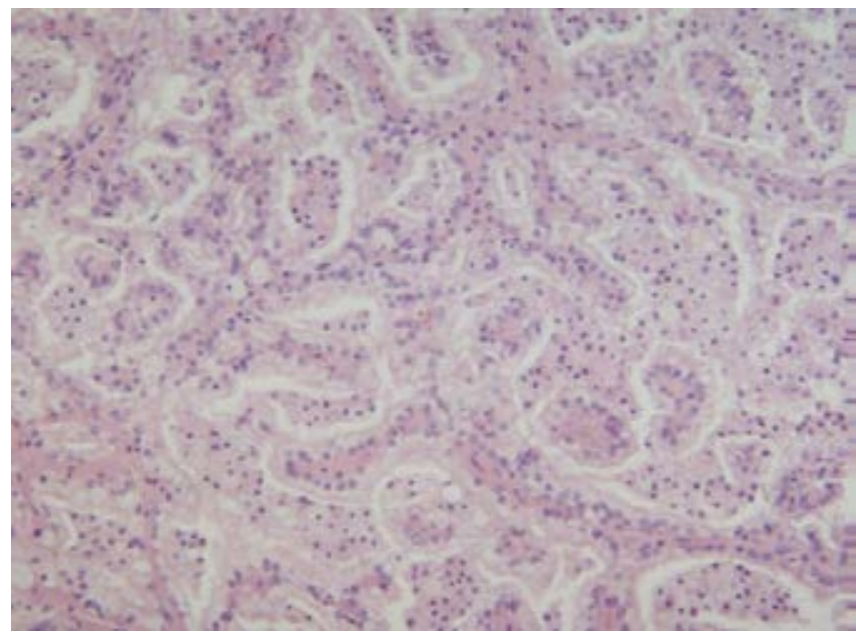

Figure 3: Biopsy Case\#3.

dialysis and transplant patients due to immunosuppression and dialysis related factors [4]. Trisomies of 3q, 7, 12, 16, 17, 20 and loss of $\mathrm{Y}$ chromosome are the frequent genetic abnormalities in papillary subset. Conventional clear cell carcinoma is the most common cancer of the renal tubular epithelium and is associated with abnormality of chromosome 3p6. Two of the three patients in this case report had papillary origin. The uniqueness of this case series is that all of the RCC in allograft were found to be from live donors and occurred after a span of many years. Allograft tumor cases have been reported sporadically in the transplant literature. The cause most of these cases have been due to deceased donor and origin of these tumor cells is from a donor kidney or secondary to a metastatic implant from a primary tumor of the recipient. Therefore, it is recommended to perform genetic studies to differentiate between donors versus recipient origin. In a few RCC cases, genetic studies by using fluorescence in situ hybridization (FISH) analysis have confirmed the origin of the tumor cells to be the donor kidney. Duplication and activation of MET proto-oncogene on chromosome 7q have been observed in familial and sporadic cases of papillary RCC. Interestingly, monosomy 7 and 17 was discovered by FISH in significant proportion of these tumor cells [5-7]. DNA microsatellite, which is short repetitive DNA sequences polymorphic in length and scattered throughout genome, can be analyzed and have proven to be beneficial in a case report to diagnose recipient cell origin in the grafted kidney [8]. Also, studies have shown that origin of allograft tumor is attributed to bone marrow derived cells migrating to kidney after AKI [9] or stem cells from kidney transformed to produce malignancy [10-12]. In the given cases it was difficult to perform genetic work prior to transplantation as the living donors and recipients suggested minimal risk factors for RCC such as analgesic abuse, tobacco use, cystic diseases, BK virus or dialysis. Even though a long-term follow up is not yet available but the clinical and radiological follow ups of the donors have not shown any signs of malignancy. This suggests the possibility that donor kidney harbored tumor at the time of transplantation which remained undiagnosed. However, the possibility of some genetic predisposition may be responsible to cause RCC in an allograft rather than native kidney. This could lead to malignant transformation of the cells of the graft along with low possibility of the unnoticed transplanted tumor.

Since these tumors are quite rare, therefore, no general consensus or guidelines have been implicated on the management of these 
Citation: Husain S, Perez F, Gerbi R, Goggins M, Patel A, et al. (2013) Renal Cell Carcinoma in Kindey Allografts: Case Report Series and Review of the Literature. J Nephrol Ther 3: 132. doi:10.4172/2161-0959.1000132

Page 3 of 3

\begin{tabular}{|c|c|c|c|c|c|c|}
\hline Age/Sex & Primary Disease & HD & IS & $\begin{array}{c}\text { Tumor Location/ } \\
\text { Size }\end{array}$ & Type & Donor \\
\hline $57 / F$ & SLE & - & Cyclosporine-Cellcept-Rapamune-Prednisone & $\mathrm{RK} / 1.3 \mathrm{~cm}$ & $\begin{array}{l}\text { Clear Cell } \\
\text { Grade-1 }\end{array}$ & $\begin{array}{l}\text { LRKT/Cousin } \\
\text { Zero Haplotype }\end{array}$ \\
\hline $45 / F$ & GN? & $36 \mathrm{~m}$ & Cellcept -Cyclosporine & $\mathrm{RK} / 1.3 \mathrm{~cm}$ & $\begin{array}{l}\text { Papillary Cell } \\
\text { Grade-3 }\end{array}$ & $\begin{array}{l}\text { LRKT/Sister } \\
\text { One Haplotype }\end{array}$ \\
\hline $46 / \mathrm{M}$ & GPA & - & Cyclosporine -Cellcept & $L K / 3.1 \mathrm{~cm}$ & $\begin{array}{l}\text { Papillary Cell } \\
\text { Grade-3 }\end{array}$ & LRKT/Brother \\
\hline
\end{tabular}

Table 1: The Clinical and Pathological Characteristics of the Patients.

patients. Although partial graft nephrectomy less than $4 \mathrm{~cm}$ in diameter is encouraged by Ribal et al. [13] and Chambade et al. [14] with the advantage of preserving graft function and reducing the need to start HD again which is associated with poor survival [14]. However, surgical expertise is required as coexistence of renal and peri renal inflammations make it difficult to maneuver the parenchyma. As a result, risk of hemorrhage and urinoma and even secondary total nephrectomy is high with open or laparoscopic partial or radical nephrectomy.

Another approach is to perform percutaneous thermal ablation. This minimally invasive option leads to preservation of graft function and low morbidity. A recent multicenter retrospective analysis showed that precutaneuos ablation is a safe and effective approach in treating de novo RCC in renal transplant [15]. This retrospective analysis has identified 24 tumors in 20 patients with maximal diameter of masses between $6-40 \mathrm{~mm}$, treated mostly with radiofrequency ablation or with cryoablation. This technique has proved to be beneficial as only one patient had a new tumor in a different location after 2 years of follow up and in some cases multifocal RCC were also treated. In those cases where there was complex nature of the lesions and suspicion of the multifocality of the lesion, so transplant nephrectomy was preferred.

\section{References}

1. Kasiske BL, Snyder JJ, Gilbertson DT, Wang C (2004) Cancer after kidney transplantation in the United States. Am J Transplant 4: 905-913.

2. Barama A, St-Louis G, Nicolet V, Hadjeres R, Daloze P (2005) Renal cell carcinoma in kidney allografts: a case series from a single center. Am J Transplant 5: 3015-3018.

3. Penn I (2000) Cancers in renal transplant recipients. Adv Ren Replace Ther 7: $147-156$.

4. Renshaw AA (2002) Subclassification of renal cell neoplasms: an update for the practising pathologist. Histopathology 41: 283-300.
5. DeLong MJ, Schmitt D, Scott KM, Ramakumar S, Lien YH (2003) Multicentric papillary renal carcinoma in renal allograft. Am J Kidney Dis 42: 381-384.

6. Schmidt L, Duh FM, Chen F, Kishida T, Glenn G, et al. (1997) Germline and somatic mutations in the tyrosine kinase domain of the MET proto-oncogene in papillary renal carcinomas. Nat Genet 16: 68-73.

7. Rouprêt M, Peraldi MN, Thaunat O, Chrétien Y, Thiounn N, et al. (2004) Rena cell carcinoma of the grafted kidney: how to improve screening and graft tracking. Transplantation 77: 146-148

8. Boix R, Sanz C, Mora M, Quer A, Beyer K, et al. (2009) Primary renal cell carcinoma in a transplanted kidney: genetic evidence of recipient origin. Transplantation 87: 1057-1061.

9. Kale S, Karihaloo A, Clark PR, Kashgarian M, Krause DS, et al. (2003) Bone marrow stem cells contribute to repair of the ischemically injured renal tubule. J Clin Invest 112: 42-49.

10. Gupta S, Rosenberg ME (2008) Do stem cells exist in the adult kidney? Am J Nephrol 28: 607-613.

11. Filocamo MT, Zanazzi M, Li Marzi V, Guidoni L, Villari D, et al. (2009) Rena cell carcinoma of native kidney after renal transplantation: clinical relevance of early detection. Transplant Proc 41: 4197-4201.

12. La Vecchia C, Negri E, D'Avanzo B, Franceschi S (1990) Smoking and renal cell carcinoma. Cancer Res 50: 5231-5233.

13. Ribal MJ, Rodriguez F, Musquera M, Segarra J, Guirado L, et al. (2006) Nephron-sparing surgery for renal tumor: a choice of treatment in an allograft kidney. Transplant Proc 38: 1359-1362.

14. Chambade D, Meria P, Tariel E, Vérine J, De Kerviler E, et al. (2008) Nephron sparing surgery is a feasible and efficient treatment of T1a renal cell carcinoma in kidney transplant: a prospective series from a single center. J Urol 180 2106-2109.

15. Cornelis F, Buy X, André M, Oyen R, Bouffard-Vercelli J, et al. (2011) De Novo Renal Tumors Arising in Kidney Transplants: Midterm Outcome after Percutaneous Thermal Ablation. Radiology 260: 900-907. 